\title{
A Comparison of Scleral Tunnel and Pericardial Graft Implantation Techniques in Patients undergoing Ahmed Glaucoma Valve Implantation
}

\author{
Medhat A Bakr ${ }^{1}$ \& Shaikha Al-Eid ${ }^{2}$ \\ ${ }^{1}$ Department of Ophthalmology,College of Medicine, Immam Abdulrahman Bin Faisal University, King Fahd \\ University Hospital, Al-khobar, Saudi Arabia \\ ${ }^{2}$ King Fahd University Hospital, Al-Khobar Saudi Arabia \\ Correspondence: Medhet Bakr, MBBcH, Ms, MD, PHD, FRCSgl, Department of Ophthalmology,College of \\ medicine,Immam Abdulrahman Bin Faisal University, King Fahd University Hospital, Al-khobar, Saudi Arabia.
}

\author{
Received: September 19, 2020 Accepted: December 16, 2020 Online Published: December 23, 2020 \\ doi:10.5539/gjhs.v13n2p27 \\ URL: https://doi.org/10.5539/gjhs.v13n2p27
}

\begin{abstract}
The purpose of this study was to compare the two methods autologous scleral flap (scleral tunnel) and pericardial patch graft of tube covered in Ahmed glaucoma valve (AGV) in refractory glaucoma with respect to the tube exposure, infection, level of Intraocular Pressure (IOP), and any other complications due to applications of each technique. A retrospective chart review of 113 eyes in 102 patients with refractory glaucoma who underwent ahmed glaucoma valve (AGV) implantation (39 eyes in scleral tunnel and scleral flap group "first group" and 74 eyes in pericardium graft group" second group") was performed. The procedures in these eyes were performed between January 2007 and October 2015 in a tertiary eye care hospital in KSA. The mean age was $56 \pm 19(8$ months- 83 years) in the Scleral tunnel group and $50 \pm 27(1-78$ years $)$ in the Pericardium group $(p=0.023)$. Fifty-six males and 57 females were included in the study. Medians of the follow-up were $48 \pm 25.5$ months $(3-89)$ for the Scleral tunnel group and $29 \pm 21.4$ months $(2-92)$ for the Pericardium group, and it is statistically significant $(\mathrm{P}<0.001)$. According to the findings, preoperative diagnosis in the two groups included neovascular glaucoma (NVG) found in 21 eyes $(53.8 \%)$ in the Scleral tunnel group versus 18 eyes $(24.3 \%)$ in the Pericardium group $(\mathrm{p}=0.009)$. Exposure of the valve was found in 15 eyes $(20.27 \%)$ in Pericardium graft group versus 2 eyes $(5.12 \%)$ only in scleral tunnel group $(\mathrm{p}=0.002)$. These exposed valves lead to endophthalmitis in 5 cases in the second group and no single case in scleral tunnel group was detected $(\mathrm{P}<0.001)$. The postoperative IOP values were statistically insignificant in all different time periods.
\end{abstract}

Scleral tunnel method has less exposure rate than the pericardium graft.

Keywords: Ahmed glaucoma valve, neovascular glaucoma, pericardial patch graft, refractory glaucoma, scleral tunnel

\section{Introduction}

Glaucoma drainage devices (GDD) has been well-established as a treatment of refractory glaucoma in which conventional filtering surgery has failed, or as primary filtration procedure long time ago (Gedde et al., 2012). The refractory glaucoma includes eyes with neovascular glaucoma, congenital glaucoma, uveitic glaucoma, glaucoma in aphakia and pseudophakia, glaucoma associated with trauma, vitreoretinal disorders, penetrating keratoplasty and eyes that have failed previous filtration surgery (Schwartz, Lee, \& Gedde, 2006; Assaad, Baerveldt, \& Rockwood, 1999; Budenz et al., 2011).

Many devices have been developed to aid angle filtration by shunting aqueous to a site away from the limbus. These devices' tubes are placed in the anterior chamber, in the ciliary sulcus, or through the pars plana into the vitreous cavity in vitrectomized eyes. Aqueous flows to the subconjunctival space where the extraocular plate is located (Budenz et al., 2011; Weinreb \& Mills, 1998; Pine \& Murphy 2005). According to their resistance to the aqueous outflow, these devices are classified into valved and non-valved tubes. The earliest and the most common use of the non-valved tubes is the Molteno implant and the Baerveldt implant. Major advances were made by Theodore Krupin in 1979 with the introduction of Krupin valve (Lim et al. 1998) and by Abdul Mateen Ahmed with the entry of Ahmed Glaucoma Valve (AGV) to the market in 1993 (Farrokh-Siar et al., 2008). The most 
widely used valved device is the Ahmed (New World Medical, Inc, Rancho Cucamonga, Ca), which allows one-way regulation of the flow with a goal of keeping the intraocular pressure (IOP) between 8 and 10 in the early post-operative period (Budenz et al., 2011). It has different models such as FP7, FP8, S2 and S3 (according to patient age and plate surface area) (Coleman et al., 1995; Ayyala et al., 2000).

The most common devastating shunt-specific delayed complication is tube exposure due to conjunctival erosion. Tube exposure following conjunctival erosion in AGV implant appeared to be a major risk factor for the development of endophthalmitis (Chen, Bhatia \& Walton, 2005; Al-Torbak \& Edward, 2001; Minckler et al., 2008; Al-Torbak et al., 2005). Different mechanisms were mentioned explaining the cause of conjunctival melting and erosion. Tube exposure may be due to immune mediated process (Lama \& Fechtner, 1999), ischemic changes of conjunctiva (Dubey et al. 2013) or due to mechanical pressure by the eyelid blinking (Byun, Lee \& Park, 2009).

There are two surgical methods for tube coverage that are generally involved before it is inserted into the anterior chamber used in AGV implantation. The first method requires covering the drainage tube with an autologous scleral flap (Heuer, Budenz \& Coleman, 2001). In the second method, the drainage tube is covered with preserved tissues that include donor sclera (Freedman, 1987), Tutoplast (pericardium) (Smith, Doyle \& Ticrney Jr, 2002), dura (Brandt, 1993), preserved cornea (Rojanapongpun \& Ritch, 1996), autologous fascia lata (Wigton et al., 2014), amniotic membrane (Tanji et al., 1996; Papadaki et al., 2007; Anand et al., 2011) or Perichondrium (Chun, Kim \& Kim, 2013) ,etc.

Since few studies were found comparing the two methods of tube covering by scleral flap and pericardial patch from the complication and IOP control sides (Huddleston et al., 2013), this study aims to compare the long-term surgical outcomes between these two methods.

\section{Method}

This study retrospectively reviewed the medical records of all the patients who underwent AGV implantation in a tertiary eye care hospital in Saudi Arabia between January 2007 and October 2015 after research and ethics committee in Al Imam Abdulrahman Bin Faisal University accepted the proposal. Pre-operative data were collected including age, sex, preoperative IOP, the number of pre-operative anti glaucoma medications used and the preoperative best-corrected visual acuity (BCVA).

All the patients underwent Optic nerve OCT analysis, corneal pachymetry measurement, and Humphrey Visual field 24-2 test. The date of surgery and type of anesthesia were recorded by the researcher. Post-operative data were collected including IOP in 7 time periods, AC formation, complications, valve explanation, number of postoperative antiglaucoma medication if needed, the post-operative best-corrected visual acuity (BCVA), and follow up duration.

The patients included in the study were: (1) all cases of refractory glaucoma including NVG, congenital glaucoma, uveitic glaucoma and other types of secondary glaucoma; (2) all cases with IOP $>21 \mathrm{mmHg}$ in spite of using full anti glaucoma medications; (3) all patients with progressive glaucomatous optic neuropathy and maximum anti glaucoma medication usage; and (4) patients who underwent failed trabeculectomy. The patients excluded from the study were: (1) all the cases with visual acuity of hand motion vision or worse; (2) all immunocompromised patients; (3) all the patients implanted with any glaucoma drainage device before AGV or implanted AGV as second valve procedure.

Young patients under age of 20 years underwent general anesthesia while other older patients underwent local anesthesia. A total of two surgical methods were performed: First one was the scleral flap, which comprised of silicon AGV implantation (models FP7 or FP8 according to the age of the patient) using a standardized surgical technique by two surgeons. After administration of regional or general anesthesia, a fornix-based conjunctival flap was fashioned in the superotemporal quadrant. Then, a U-shaped partial thickness scleral flap 4x5 mm, medial or lateral canthus based was formed. After the excision of redundant Tenon's capsule, a large single Weck-cell sponge soaked in a $0.2 \mathrm{mg} / \mathrm{mL}$ solution of MMC was placed under the conjunctiva and the Tenon's capsule at the site where the implant plate was to be placed, for a contact time of 2 minutes. The application of the sponge was followed by irrigation with at least $50 \mathrm{~mL}$ of balanced salt solution (BSS). The anterior edge of the plate was then secured with 7-0 Prolene sutures (PROLENE® Polypropylene Suture; Ethicon, Inc, Somerville, New Jersey, USA) to the sclera at least $8-10 \mathrm{~mm}$ away from the limbus. The tube tip was cut obliquely beveling up to avoid the tube lumen obstruction by the iris tissue and to protect the cornea from being touched by the tip of the tube. Viscoelastic was injected to maintain the anterior chamber before tube implantation, then a 23-gauge needle tract was used to enter the anterior chamber through the limbus. The tube in the anterior chamber was positioned anterior to the iris and away from the corneal endothelium. Scleral flap was sutured by 7-0 Prolene sutures (PROLENE®) 
Polypropylene Suture; Ethicon, Inc, Somerville, New Jersey, USA). The conjunctiva and Tenon capsule were re-approximated to the limbus with 8-0 Polyglactin sutures (Vicryl; Ethicon, Inc, Somerville, New Jersey, USA) or 10-0 Nylone sutures (ETHILON® Nylon suture; Ethicon, Inc, Somerville, New Jersey, USA) were used based on the preferences of researchers.

In scleral tunnel technique, Bever blade was used to make a horizontal half thickness scleral wound 6-8 $\mathrm{mm}$ from the limbus. With crescent blade, two consecutive tunnels of $3 \mathrm{~mm}$ width and 3-4 $\mathrm{mm}$ length were made till the limbus to facilitate the tube manipulation. After that, engagement of anterior chamber was done by 23 -gauge needle under viscoelastic material in anterior chamber and implantation of the tube after trimming its tip.

In the second method, pericardium graft was used where same technique creates the conjunctival flap. After securing the plate to the sclera, $5 \mathrm{~mm} \times 4 \mathrm{~mm}$ pericardial graft was applied over the tube till the limbus and secured with 4 sutures of 10-0 Nylon suture (ETHILON® Nylon suture; Ethicon, Inc, Somerville, New Jersey, USA) at the corners of the graft.

The postoperative regimen included topical antibiotics for 2 weeks, topical cycloplegics and topical steroids for approximately 1 month. Anti-glaucoma medication was added when required to improve IOP reduction. Patients were examined in the following intervals; the next day of the surgery, the $1^{\text {st }}$ week, the $1^{\text {st }}$ month, the $3^{\text {rd }}$ month, the $6^{\text {th }}$ month and then annually after surgery as follow up.

\subsection{Statistical Analysis}

Statistical analysis was done by SPSS version 20.0 (SPSS Inc., Chicago, IL, USA). Preoperative and postoperative data were compared using the paired t-test. Two groups were compared using the Mann-Whitney U-test and Chi square or Fisher's exact test. The postoperative complications were compared using Chi-square test or Fisher's exact test. A p-value of less than 0.05 was considered statistically significant.

\section{Results}

This study investigated 113 eyes in 102 patients, in which 39 eyes underwent scleral flap method of AGV implantation in upper temporal quadrant and 74 eyes underwent the pericardium graft method. One valve on each group ( 2 total) was implanted in inferio-nasal side due to severe conjunctival fibrosis in upper temporal quadrant after previous glaucoma surgery.

The mean age were $56 \pm 19$ years ( 8 months- 83 years) in the Scleral tunnel group and $50 \pm 27.7$ years (1- 78 years) in the Pericardium group $(\mathrm{p}=0.023)$. Fifty-six patients were males and fifty-seven were females in the two groups with no statistically difference $(\mathrm{p}=0.897)$. Median with range of the follow-up periods were $48 \pm 25.5$ months $(3-$ 89 ) for the Scleral tunnel group and $29 \pm 21.4$ months $(2-92)$ for the Pericardium group, and it was statistically significant $(\mathrm{P}<0.001)$. Diabetes mellitus was found in around half of the overall patient, while hypertension was found in around $34 \%$ of all patients (Table 1). The means of preoperative IOP were $39.58 \pm 12.13 \mathrm{mmHg}$ in scleral tunnel group and $32.80 \pm 8.04 \mathrm{mmHg}$ in pericardium graft group, which is statistically significant $(\mathrm{P}=0.003)$.

Table 1. Characteristics of patients

\begin{tabular}{llll}
\hline & Scleral flap group & Pericardium group & P value \\
\hline Age & $56 \pm 19(8$ months- 83 years $)$ & $50 \pm 27.7(1-78$ years $)$ & $0.023^{*}$ \\
\hline Sex & $19(48.7 \%)$ & $37(50 \%)$ & 0.897 \\
Male & $20(51.3 \%)$ & $37(50 \%)$ & 0.231 \\
Female & $23(58.97 \%)$ & $33(44.59 \%)$ & $0.003^{*}$ \\
\hline DM & $12(30.76 \%)$ & $28(37.83 \%)$ & $<0.001^{* *}$ \\
\hline HTN & $39.5897 \pm 12.13$ & $32.8028 \pm 8.04$ & $29 \pm 21.4(2-92)$ \\
\hline Pre op IOP & $48 \pm 25.5(3-89)$ & & \\
\hline Follow up & & & \\
\hline
\end{tabular}

* significant at $\mathrm{p}<0.05 ; * *$ significant at $\mathrm{p}<0.10$

The mean number of pre-operative anti-glaucoma medications number was $3.97 \pm 0.4$ in scleral tunnel group versus $3.35 \pm 0.9$ in pericardium graft group $(\mathrm{p}<0.001)$. In comparison, post-operative medication number shows 
higher reduction in pericardium graft group than in scleral tunnel group. The mean number post-operative anti glaucoma medications was $2.64 \pm 1.4$ in scleral tunnel group and $1.9 \pm 1.6$ in pericardium graft group $(\mathrm{P}=0.02)$ (Table 2).

Table 2. Comparison between pre- and post-operative medication number in both groups

\begin{tabular}{llll}
\hline & Scleral tunnel & Pericardium & P value \\
\hline Pre op Medication & $3.97 \pm 0.4$ & $3.35 \pm 0.9$ & $<0.001$ \\
Post op Medication & $2.64 \pm 1.4$ & $1.9 \pm 1.6$ & $0.020^{*}$ \\
\hline
\end{tabular}

* significant at $\mathrm{p}<0.05$.

The most common pre-operative diagnosis in this study was neovascular glaucoma (NVG) followed by congenital glaucoma. In the two groups, NVG associated with proliferative diabetic retinopathy (PDR) or central retinal vein occlusion (CRVO) was found in 21 eyes $(53.8 \%)$ in the Scleral tunnel group versus 18 eyes $(24.3 \%)$ in the Pericardium group $(\mathrm{p}=0.009)$. On the other hand, congenital glaucoma was found in 2 eyes $(5.12 \%)$ in the scleral tunnel group versus 22 eyes $(29.72 \%)$ in the pericardium graft group $(p=0.009)$. Other pre-operative diagnoses are listed in Table 3.

Table 3. Preoperative diagnoses of patients

\begin{tabular}{|c|c|c|c|c|c|}
\hline & & \multicolumn{2}{|l|}{ Method } & \multirow{2}{*}{$\begin{array}{l}\text { Total } \\
\text { Eyes/Patients }\end{array}$} & \multirow[b]{2}{*}{ P value } \\
\hline & & $\begin{array}{l}\text { Scleraltunnel } \\
\text { Eyes/ Patiens }\end{array}$ & $\begin{array}{l}\text { Pericardium } \\
\text { Eyes/ Patients }\end{array}$ & & \\
\hline \multirow{11}{*}{ Diagnose } & $\mathrm{NVG}$ & $21(53.84 \%) / 19$ & $18(24.32 \%) / 17$ & $39 / 36$ & \multirow{11}{*}{0.009} \\
\hline & Congenital glaucoma & $2(5.12 \%) / 2$ & $22(29.72 \%) / 17$ & $24 / 19$ & \\
\hline & Advance primary open angle & $2(5.12 \%) / 2$ & $13(17.56 \%) / 12$ & $15 / 14$ & \\
\hline & Secondary closed angle & $4(10.24 \%) / 4$ & $11(14.86 \%) / 11$ & $15 / 15$ & \\
\hline & ICE syndrome & $2(5.12 \%) / 2$ & $1(1.35 \%) / 1$ & $3 / 3$ & \\
\hline & Juvenile glaucoma & $1(2.55 \%) / 1$ & $2(2.70 \%) / 2$ & $3 / 3$ & \\
\hline & PXF & $1(2.55 \%) / 1$ & $1(1.35 \%) / 1$ & $2 / 2$ & \\
\hline & Combined mechanism & $1(2.55 \%) / 1$ & $1(1.35 \%) / 1$ & $2 / 2$ & \\
\hline & Uvetic glaucoma & $2(5.12 \%) / 2$ & $4(5.40 \%) / 3$ & $6 / 5$ & \\
\hline & Aphakic glaucoma & $3(7.59 \%) / 2$ & $1(1.35 \%) / 1$ & $4 / 3$ & \\
\hline & Total & $39 / 36$ & $74 / 66$ & $113 / 102$ & \\
\hline
\end{tabular}

The mean pre-operative IOP value in the Scleral tunnel group was $39.56 \pm 12.1 \mathrm{mmHg}$ versus $32.8 \pm 8.0 \mathrm{mmHg}$ in the Pericardium group and it was statistically significant $(p=0.003)$. The postoperative IOP was taken in different time periods. The first reading was taken in the first day post-operatively, where the mean IOP was $9.47 \pm 5.4 \mathrm{~mm}$ in scleral tunnel group "toward hypotony side" and the mean IOP was $11.7 \pm 6.4 \mathrm{~mm}$ in the other group with no significant $p$ value. IOP was taken regularly for all the patients in the first week, the first month, the third month, the sixth month after the surgery, and then yearly afterwards. All of these values were statistically insignificant between both groups as shown in Table 4 and Figure 1 . 
Table 4. IOP values on 7 follow up time periods

\begin{tabular}{llll}
\hline Time Periods & Scleral tunnel & Pericardium & P value \\
\hline First day post op & $9.47 \pm 5.4$ & $11.7 \pm 6.4$ & 0.079 \\
First week Post Op & $10.8 \pm 7.8$ & $10.7 \pm 5.7$ & 0.993 \\
First month Post Op & $17.10 \pm 9.6$ & $15.4 \pm 8.4$ & 0.366 \\
Third month Post OP & $16.5 \pm 8.7$ & $16.0 \pm 7.4$ & 0.799 \\
6th month Post Op & $18.0 \pm 10.1$ & $15.9 \pm 8.7$ & 0.314 \\
First Year Post OP & $18.16 \pm 14.2$ & $15.4 \pm 6.6$ & 0.236 \\
Second year post op & $15.9 \pm 6.2$ & $16.7 \pm 8.4$ & 0.664 \\
\hline
\end{tabular}

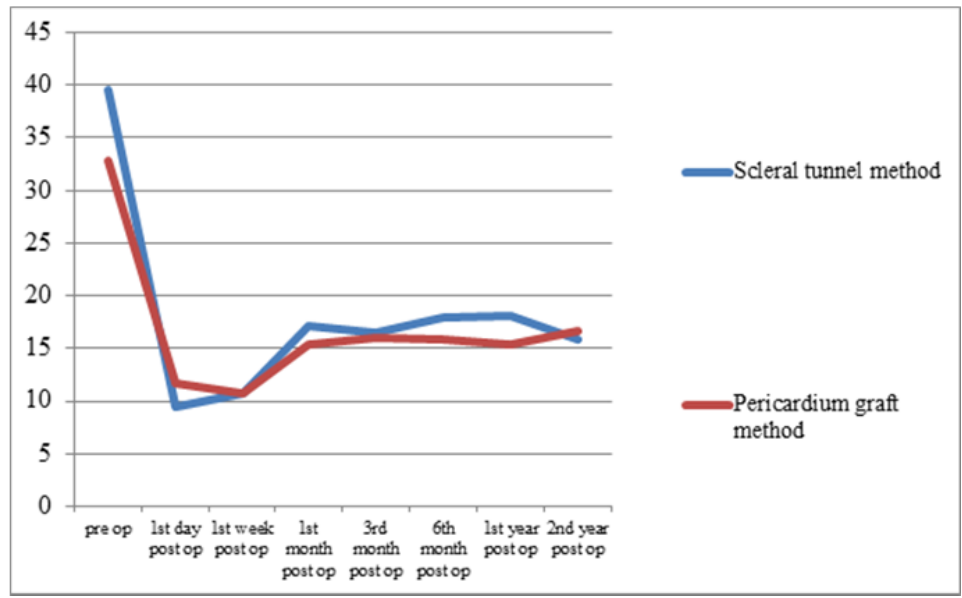

Figure 1. IOP values on 7 follow up time periods

There was no significant difference in preoperative and postoperative BCVA in the two groups $(\mathrm{p}=0.171$ and $\mathrm{p}=$ 0.239 , respectively) (Figure 2).

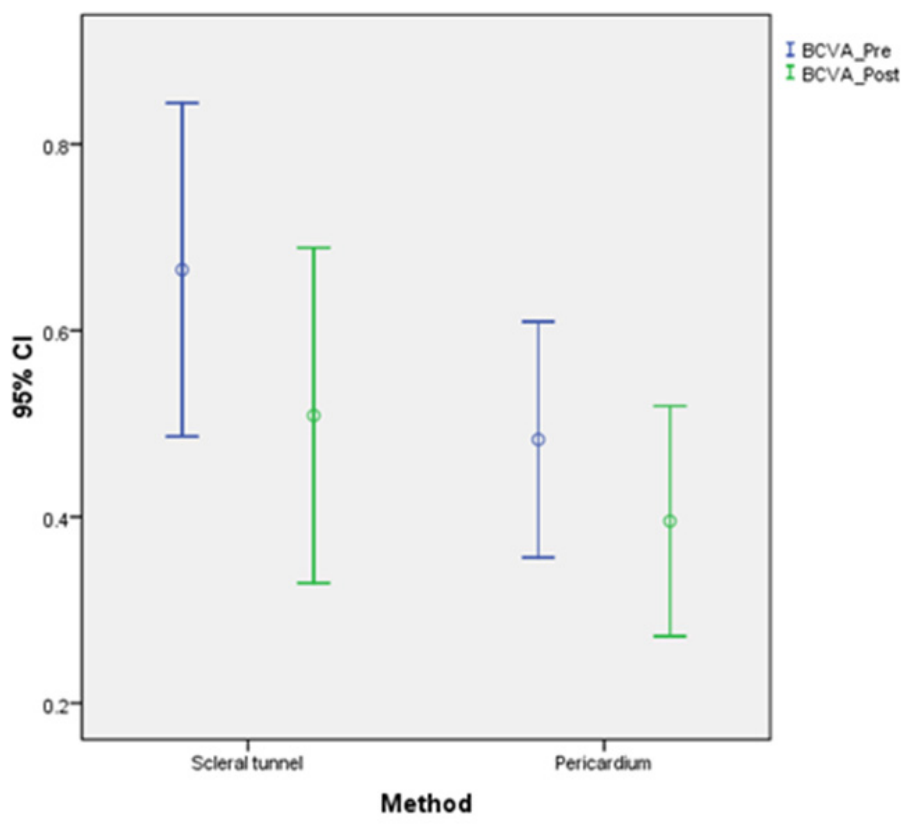

Figure 2. Preoperative and postoperative BCVA 
This study mainly focuses on the complications occurred after each method of tube covering. Tube exposure occur in 2 cases only of scleral tunnel method compared with 15 cases of pericardium graft method, which was highly statistically significant $(\mathrm{p}=0.002)$. Hence, endophthalmitis occurred in 5 cases with exposed valve in pericardium graft versus no exposed valve in scleral tunnel group develop endophthalmitis $(\mathrm{p}<0.001)$. In contrast, choroidal detachment was discovered in 5 cases of patient who underwent scleral tunnel method only, which could be explained by hypotony that occurs in the first few days after the flap surgery $(\mathrm{p}<0.001)$. Other complications with insignificant difference between each group are listed in Table 5.

Table 5. Postoperative Complications

\begin{tabular}{llcc}
\hline \multicolumn{2}{c}{ No of Eyes } & \\
\hline Complications & Scleral tunnel & Pericardium & -value \\
\hline Exposure & $2(5.12 \%)$ & $15(20.27 \%)$ & $0.002^{*}$ \\
Endophthalmitis & $0(0 \%)$ & $5(6.75 \%)$ & $<0.001^{* *}$ \\
Bollus keratopathy & $4(10.25 \%)$ & $8(10.81 \%)$ & 0.248 \\
Occlusion & $5(12.82 \%)$ & $6(8.10 \%)$ & 0.763 \\
Choroidal detachment & $5(12.82 \%)$ & $0(0 \%)$ & $<0.001^{* *}$ \\
Hyphema & $1(2.56 \%)$ & $2(2.70 \%)$ & 0.564 \\
\hline
\end{tabular}

* significant at $\mathrm{p}<0.05 ; * *$ significant at $\mathrm{p}<0.10$.

Anterior chamber (AC) formation has been studied in this study and showed a shallow AC in 7 eyes in scleral tunnel group versus two eyes in pericardium graft group $(\mathrm{p}<0.001)$. Only 2 cases from the first group were associated with choroidal detachment. Moreover, four eyes (44.44\%) of these 9 eyes with shallow AC were in need of $\mathrm{AC}$ reformation (by air or viscoelastic material only) and they were from the first group. The remaining eyes with shallow $\mathrm{AC}$ were spontaneously formed. Table 6 compares the $\mathrm{AC}$ formation between the two groups.

Table 6. AC formation in both groups

\begin{tabular}{llll}
\hline AC formation & Scleral tunnel & Pericardium & P value \\
\hline Formed & $32(82.05 \%)$ & $72(97.29 \%)$ & $<0.001^{*}$ \\
Shallow & $7(17.94 \%)$ & $2(2.70 \%)$ & \\
\hline
\end{tabular}

* significant at $\mathrm{p}<0.05$.

Regarding tube's explanation, 6 tubes $(15.38 \%)$ were explanted in scleral tunnel group versus 10 tubes $(13.51 \%)$ in pericardium graft group with no statistically significant difference $(\mathrm{p}=0.808)$ (Table 7). Out of those 16 tubes, 10 tubes were explanted due to tube exposure, 3 tubes were explanted due to persistence hypotony and other 3 tubes were explanted due to bollus keratopathy after corneal touch.

Table 7. Number of explanted tubes in both groups

\begin{tabular}{llll}
\hline Valve explanation & Scleral tunnel & Pericardium & P value \\
\hline Not Explant & $33(84.61 \%)$ & $64(86.48 \%)$ & 0.808 \\
Explant & $6(15.38 \%)$ & $10(13.51 \%)$ & \\
\hline
\end{tabular}

The complete success is defined as the percentage of patients post AGV implantation with $\mathrm{IOP}<21 \mathrm{~mm} \mathrm{Hg}$ without using any anti glaucoma medication. Qualified success was defined as the percentage of patients post AGV implantation with IOP $<21 \mathrm{~mm} \mathrm{Hg}$ and with intake of anti-glaucoma medication. Finally, failure rate was defined as all patient post AGV implantation with $\mathrm{IOP}>21 \mathrm{~mm} \mathrm{Hg}$ in spite of using maximum anti glaucoma medication. In additional to eyes requiring further glaucoma surgery (including needling, encapsulated cyst 
excision, cyclophotocoagulation or removal of the implant) or eyes that lost light perception were classified as failures. These rates between the 2 groups are shown in Table 8 .

Table 8. Success and failure rates

\begin{tabular}{llll}
\hline & Scleral tunnel & Pericardium & p-values \\
\hline Complete success rate & $3(7.69 \%)$ & $19(25.67 \%)$ & $>0.001$ \\
Qualified success rate & $23(58.97 \%)$ & $39(52.7 \%)$ & $>0.001$ \\
Failure rate & $13(33.33 \%)$ & $16(21.62 \%)$ & $>0.001$ \\
\hline
\end{tabular}

\section{Discussion}

To the best of researcher's knowledge, there were just a few studies that discussed the scleral flap covering AGV. This study has compared the surgical outcomes of the two methods covering the tube for AGV implantation. In our study, the scleral tunnel group and pericardium graft group did not show significant differences in terms of postoperative IOP. The complete success was higher in Pericardium graft group. Qualified success was higher in scleral flap group compared to the pericardium graft group by $6 \%$ only. While failure rate was higher in scleral tunnel group.

The findings regarding valve exposure \& IOP control were dissimilar to those recently reported by Ho Young Lee et al. (2011), who retrospectively reviewed experiences between Scleral Graft and Scleral Flap, and found no difference between flap and graft group in exposure side. This study found a big difference between the two groups, as the exposed valve was found in 15 out of 74 eyes (20.2\%) of pericardium graft group and 5 of them (33.3\%) developed Endophthalmitis. In the first group, only 2 out of $39(5.12 \%)$ cases had exposed valve without endophthalmitis. These 2 cases of scleral tunnel whose tubes got exposed were treated with Pericardium graft in same year of implantation. Unfortunately, one case ended with blind painful eye and was managed with cyclophotocoagulation. Raviv et al. (1998); in a similar study, evaluated 44 eyes that underwent glaucoma drainage device "GDD" surgery with the use of pericardium patch graft. Findings reported diffuse graft thinning in 5 cases without overlying erosion.

These findings were also in-line with Smith, Doyle and Ticrney Jr (2002) who showed that graft melting could occur as a result of a low grade, possibly immune-mediated, long term, atrophy process, with consequent gradual graft thinning or due to a mechanical process, where if the tube was not sutured totally flush to the sclera but no tube erosion per se. Tamçelik et al. (2010) found that the long scleral tunnel technique was a good way to prevent tube exposure except in congenital glaucoma cases because sclera was inherently very thin in these cases and most of the patients have had multiple previous surgeries. The exposure rate through conjunctival erosion in their study was seen in 3 of 32 patients $(9.4 \%)$. In this study, only 2 cases out of $39(5.12 \%)$ from the scleral tunnel group had exposed valve and both were not a congenital glaucoma cases.

Ollila, Falck, and Airaksinen (2005) studied the technique of scleral tunneling without a patch graft and documented the experience with 96 eyes. A mean follow up of 22 months was achieved with no exposures occurring.

Regarding the timing of valve exposure, this study found that; in scleral tunnel group, 1 case developed exposure in 2 months while in another case it was developed in the duration of 2 years. In pericardium graft group, this study has found that around 2 cases of exposed valve happen in less than 1-month period, 7 cases in less than 1 year and 6 cases in less than 2 years, respectively.

A meta-analysis of the incidence of conjunctival erosion after any GDD implantation suggests that tube exposure of glaucoma implants was unusual and the incidence does not differ between the Ahmed, Baerveldt, and Molteno implants. However, exposure may occur at any time within the first 5 years following implantation. This result is similar to the findings of the present study that showed different timing of valve exposure and implantation (Stewart et al., 2010).

In comparison, 5 eyes from the first group developed choroidal detachment post operatively while none had the same in the second group. Most of these cases were managed medically with Steroid and Atropine Drops and no surgery were needed.Coleman et al. (1995) found that choroidal detachment was the most common complication that usually occurs after AGV implantation "regardless of tube's cover type". It was reported in 13 out 60 patients (22\%) (Coleman et al., 1995). 
Two cases had shallow anterior chamber or early hypotony in the pericardium graft group, which were spontaneously resolved in the postoperative first week. In comparison, four eyes that had persistent shallow anterior chamber "AC" in the flap group were treated with AC formation by intra-cameral injection of viscoelastic or air. This can be explained by the leaking aqueous through the wide opening created for tube insertion in the angle that seems wider than the tube diameter itself. This can be avoided by tightening the sutures or increasing its numbers. In Lee et al. (2011) study, shallow AC was found in four eyes (40.0\%) in flap group versus seven eyes (38.9\%) with shallow AC in scleral graft group.

A 31 years old male, known case of Uveitic Glaucoma underwent AGV implantation by scleral tunnel method in Jan 2009 after being on 4 types of topical anti-glaucoma medications. The implanted tube touched the corneal endothelium 3 years after, and corrected surgically by tube repositioning. The patient developed corneal decompensation and the tube was rotated 2 times after first correction and then corrected with repositioning for the second time. The tube was finally explanted in September 2013. Corneal decompensation was managed by Penetrating Keratoplasty in 2015.

Majority of explanted valves (16 valves) were based on valve exposure $(62.5 \%)$ while $(18.75 \%)$ were explanted due to hypotony, and other $(18.75 \%$ ) were due to bollus keratopathy. Byun, Lee \& Park (2009) found that tube exposure was hard to be corrected, especially in case of infection. The best solution could be to remove the implant.

One of the main limitations found with Pericardium covered tubes was orbital cellulitis. One-year-old male and another 65 years old male patient developed orbital cellulitis in 2 months and 1-month post AGV implantation respectively. Unfortunately, evisceration was done in both cases after failure of medical treatment. Lee et al. (2011) found migration of the tube in $30 \%$ of the flap group while in our study no migration of the tubes where noticed in both groups.

The limitations of our study are variation of follow up period between 2 months and 92 months in some patients. The unequal number of cases between each group is another limitation. Third limitation is the wide range of patient's ages.

Scleral tunnel method of covering AGV implanted in refractory glaucoma has less exposure rate than the pericardium graft where some exposed valves in pericardium graft cases developed endophthalmitis. However, Scleral tunnel method shows significantly decreased IOP values post-operatively and this hypotony lead to choroidal detachment in some cases but it is limited.

\section{Competing Interests Statement}

The authors declare that there are no competing or potential conflicts of interest.

\section{References}

Al-Torbak, A. A., Al-Shahwan, S., Al-Jadaan, I., Al-Hommadi, A., \& Edward, D. P. (2005). Endophthalmitis associated with the Ahmed glaucoma valve implant. British Journal of Ophthalmology, 89(4), 454-458. https://doi.org/10.1136/bjo.2004.049015

Al-Torbak, A., \& Edward, D. P. (2001). Transcorneal tube erosion of an Ahmed valve implant in a child. Archives of Ophthalmology, 119(10), 1558-1559. https://doi.org/10.1001/archopht.119.10.1558

Anand, A., Sheha, H., Teng, C. C., Liebmann, J. M., Ritch, R., \& Tello, C. (2011). Use of amniotic membrane graft in glaucoma shunt surgery. Ophthalmic Surgery, Lasers and Imaging Retina, 42(3), 184-189. https://doi.org/10.3928/15428877-20110426-01

Assaad, M. H., Baerveldt, G., \& Rockwood, E. J. (1999). Glaucoma drainage devices: pros and cons. Current Opinion in Ophthalmology, 10(2), 147-153. https://doi.org/10.1097/00055735-199904000-00012

Ayyala, R. S., Michelini-Norris, B., Flores, A., Haller, E., \& Margo, C. E. (2000). Comparison of different biomaterials for glaucoma drainage devices: part 2. Archives of Ophthalmology, 118(8), 1081-1084. https://doi.org/10.1001/archopht.118.8.1081

Brandt, J. D. (1993). Patch grafts of dehydrated cadaveric dura mater for tube-shunt glaucoma surgery. Archives of Ophthalmology, 111(10), 1436-1439. https://doi.org/10.1001/archopht.1993.01090100144042

Budenz, D. L., Barton, K., Feuer, W. J., Schiffman, J., Costa, V. P., Godfrey, D. G., \& Buys, Y. M. (2011). Treatment Outcomes in the Ahmed Baerveldt Comparison Study after 1 Year of Follow-up. Ophthalmology, 118(3), 443-452. https://doi.org/10.1016/j.ophtha.2010.07.016

Byun, Y. S., Lee, N. Y., \& Park, C. K. (2009). Risk factors of implant exposure outside the conjunctiva after 
Ahmed glaucoma valve implantation. Japanese journal of ophthalmology, 53(2), 114-119. https://doi.org/10.1007/s10384-008-0630-y

Chen, T. C., Bhatia, L. S., \& Walton, D. S. (2005). Ahmed valve surgery for refractory pediatric glaucoma: a report of 52 eyes. Journal of pediatric ophthalmology and strabismus, 42(5), $274-283$. https://doi.org/10.3928/0191-3913-20050901-09

Chun, Y. S., Kim, K. W., \& Kim, J. C. (2013). Autologous tragal perichondrium patch graft for ahmed glaucoma valve tube exposure. Journal of glaucoma, 22(9), e27-e30. https://doi.org/10.1097/IJG.0b013e318255dc1c

Coleman, A. L., Hill, R., Wilson, M. R., Choplin, N., Kotas-Neumann, R., Tam, M. A. E., ... \& Panek, W. C. (1995). Initial clinical experience with the Ahmed glaucoma valve implant. American journal of ophthalmology, 120(1), 23-31. https://doi.org/10.1016/S0002-9394(14)73755-9

Dubey, S., Prasanth, B., Acharya, M. C., \& Narula, R. (2013). Conjunctival erosion after glaucoma drainage device surgery: a feasible option. Indian journal of ophthalmology, 61(7), 355. https://doi.org/10.4103/0301-4738.99852

Farrokh-Siar, L., Chen, T. C., Facs, M., \& Krupin, T. (2008). Surgical techniques in ophthalmology series: glaucoma surgery. Elsevier.

Freedman, J. (1987). Scleral patch grafts with Molteno setons. Ophthalmic Surgery, Lasers and Imaging Retina, $18(7), 532-534$.

Gedde, S. J., Schiffman, J. C., Feuer, W. J., Herndon, L. W., Brandt, J. D., Budenz, D. L., \& Tube versus Trabeculectomy Study Group. (2012). Treatment outcomes in the Tube Versus Trabeculectomy (TVT) study after five years of follow-up. American Journal of Ophthalmology, 153(5), 789-803. https://doi.org/10.1016/j.ajo.2011.10.026

Heuer, D. K., Budenz, D., \& Coleman, A. (2001). Aqueous shunt tube erosion. Journal of glaucoma, 10(6), 493-496. https://doi.org/10.1097/00061198-200112000-00010

Huddleston, S. M., Feldman, R. M., Budenz, D. L., Bell, N. P., Lee, D. A., Chuang, A. Z., ... \& Moraczewski, A. (2013). Aqueous shunt exposure: a retrospective review of repair outcome. Journal of glaucoma, 22(6), 433-438. https://doi.org/10.1097/IJG.0b013e3181f3e5b4

Lama, P. J., \& Fechtner, R. D. (1999). Tube erosion following insertion of a glaucoma drainage device with a pericardial patch graft. Archives of Ophthalmology, 117(9), 1243-1244. https://doi.org/10.1001/archopht.117.9.1243

Lee, H. Y., Park, J. S., Choy, Y. J., \& Lee, H. J. (2011). Surgical outcomes of different Ahmed Glaucoma Valve implantation methods between scleral graft and scleral flap. Korean Journal of Ophthalmology, 25(5), 317-322. https://doi.org/10.3341/kjo.2011.25.5.317

Lim, K. S., Allan, B. D. S., Lloyd, A. W., Muir, A., Khaw, P. T., Lim, K. S., ... \& Khaw, P. T. (1998). Glaucoma drainage devices; past, present, and future. British Journal of Ophthalmology, 82(9), 1083-1089. https://doi.org/10.1136/bjo.82.9.1083

Minckler, D. S., Francis, B. A., Hodapp, E. A., Jampel, H. D., Lin, S. C., Samples, J. R., ... \& Singh, K. (2008). Aqueous shunts in glaucoma: a report by the American Academy of Ophthalmology. Ophthalmology, 115(6), 1089-1098. https://doi.org/10.1016/j.ophtha.2008.03.031

Ollila, M., Falck, A., \& Airaksinen, P. J. (2005). Placing the Molteno implant in a long scleral tunnel to prevent postoperative tube exposure. Acta Ophthalmologica Scandinavica, 83(3), 302-305. https://doi.org/10.1111/j.1600-0420.2005.00450.x

Papadaki, T. G., Siganos, C. S., Zacharopoulos, I. P., Panteleontidis, V., \& Charissis, S. K. (2007). Human amniotic membrane transplantation for tube exposure after glaucoma drainage device implantation. Journal of Glaucoma, 16(1), 171-172. https://doi.org/10.1097/01.ijg.0000212292.93292.80

Pine, J., \& Murphy, J. (2005). Drainage implant surgery. In R. R. Allingham, K. F. Damji, \& S. Freedman (Eds.), Shields Textbook of glaucoma (5th ed.). Philadelphia: Lippincott Willliams \& Wilkins, 6100-25.

Raviv, T., Greenfield, D. S., Liebmann, J. M., Sidoti, P. A., Ishikawa, H., \& Ritch, R. (1998). Pericardial patch grafts in glaucoma implant surgery. Journal of glaucoma, $7(1), 27-32$. https://doi.org/10.1097/00061198-199802000-00006

Rojanapongpun, P., \& Ritch, R. (1996). Clear corneal graft overlying the seton tube to facilitate laser suture lysis. 
American journal of ophthalmology, 122(3), 424. https://doi.org/10.1016/S0002-9394(14)72070-7

Schwartz, K. S., Lee, R. K., \& Gedde, S. J. (2006). Glaucoma drainage implants: a critical comparison of types. Current Opinion in Ophthalmology, 17(2), 181-189. https://doi.org/10.1097/01.icu.0000193080.55240.7e

Smith, M. F., Doyle, J. W., \& Ticrney Jr, J. W. (2002). A comparison of glaucoma drainage implant tube coverage. Journal of glaucoma, 11(2), 143-147. https://doi.org/10.1097/00061198-200204000-00010

Stewart, W. C., Kristoffersen, C. J., Demos, C. M., Fsadni, M. G., \& Stewart, J. A. (2010). Incidence of conjunctival exposure following drainage device implantation in patients with glaucoma. European journal of ophthalmology, 20(1), 124-130. https://doi.org/10.1177/112067211002000117

Tamçelik, N., Sarici, A. M., Yetik, H., Özkök, A., \& Özkiris, A. (2010). A Novel Surgical Technique to Prevent Postoperative Ahmed Valve ${ }^{\mathrm{TM}}$ Tube Exposure Through Conjunctiva: Tenon Advancement and Duplication. Ophthalmic Surgery, Lasers and Imaging Retina, 41(3), 370-374. https://doi.org/10.3928/15428877-20100430-12

Tanji, T. M., Lundy, D. C., Minckler, D. S., Heuer, D. K., \& Varma, R. (1996). Fascia laxa patch graft in glaucoma tube surgery. Ophthalmology, 103(8), 1309-1312. https://doi.org/10.1016/S0161-6420(96)30506-X

Weinreb, R. N., \& Mills, R. P., eds. (1998). Glaucoma Surgery: Principles and Techniques (2nd ed.). Ophthalmology Monograph 4. San Francisco: American Academy of Ophthalmology, 65-85.

Wigton, E., Swanner, J. C., Joiner, W., Feldman, A., McGwin Jr, G., Huisingh, C., ... \& Girkin, C. A. (2014). Outcomes of shunt tube coverage with glycerol preserved cornea versus pericardium. Journal of glaucoma, 23(4), 258-261. https://doi.org/10.1097/IJG.0b013e31826a96e8

\section{Copyrights}

Copyright for this article is retained by the author(s), with first publication rights granted to the journal.

This is an open-access article distributed under the terms and conditions of the Creative Commons Attribution license (http://creativecommons.org/licenses/by/4.0/). 